\title{
Experimental Investigation of WEDM Variables on Surface Roughness of AISI D3 Die Steel By Using Two Cryogenically Treated Different Wires
}

\author{
Navjot Singh, Parlad Kumar*, Khushdeeep Goyal \\ Department of Mechanical Engineering, Punjabi University, Patiala, 147001, Punjab, India \\ *Corresponding Author: khushgoyal@yahoo.com
}

Copyright (C) 2014 Horizon Research Publishing All rights reserved.

\begin{abstract}
In WEDM material of wire is of great importance because it affects material removal rate as well as surface finish of work piece. In this experimental work, two different wires i.e., cryogenically treated zinc coated diffused brass wire and plain brass wire has been used as cutting tool. In this study AISI D3 die steel has been taken work piece. AISI D3 tool steel is a high-carbon, high chromium, oil-hardening tool steel. Typical applications for D3 tool steel include blanking, stamping, and cold forming dies and punches for long runs; lamination dies, bending, forming, and seaming rolls, cold trimmer. The input process parameters considered in this research work are pulse width, time between two pulses, wire mechanical tension and wire feed rate. Taguchi's L9 orthogonal array has been used for design of experiments. The process performance is measured in terms of surface roughness (SR). After performing the experiment result of both wires have been compared. It is found that the cryogenically treated zinc coated diffused brass wire gives good surface finish as compare to cryogenically treated plain brass wire.
\end{abstract}

Keywords WEDM, ANOVA, Surface Roughness, S/N Ratio, Process Parameters, Cryogenic

\section{Introduction}

The Wire electrical discharge machining (WEDM) technology has grown tremendously since it was first applied more than 30 years ago. In the present study AISI D3 is used as work piece material. AISI D3 tool steel is a high-carbon, high chromium, oil-hardening tool steel that is characterized by a relatively high attainable hardness. Applications for D3 tool steel include blanking, stamping, and cold forming dies and punches for long runs; lamination dies, bending, forming, and seaming rolls, cold trimmer dies or rolls, burnishing dies or rolls, plug gauges, drawing dies for bars or wire. Because all these components are made from hard material and only
WEDM is suitable to machine these components. The effect on surface roughness has been evaluated by using two different cryogenically treated wires. Then the results for two wires have been compared.

\section{Literature Survey}

Lahaneet et al. [1] applied a number of approaches to determine the optimal process settings that can optimize multiple performance measures of WEDM operation. The authors used weighted principal component method to optimize the multiple responses of WEDM processes. The results show that the WPC method offers significantly better overall quality as compared to other approaches. Gill et al. [2] studied machined on the effect of deep cryogenic treatment on surface Roughness of OHNS Die steel machined on WEDM. Taguchi design approach was used before and after cryogenic treatment of OHNS Die steel work piece. It was found that the machining performance of WEDM relatively depends upon various input parameters but the peak current and short pulse time have been the most significant parameters. Sharma et al. [3] used the taguchi method to optimize the process parameters of cryogenic treated D-3 machined by WEDM. In this study the material was kept in cold environment to increase wear resistance and releaving residential stress. Several Process parameters as pulse width, time between two pulses, maximum feed rate, servo reference mean voltage. It was found that the pulse width and time between two pulses has significant effect on SR values. Purcar et al. [4] conducted a about roughness of surfaces machined by EDM. Eler 01 Gep 50 machine equipped with a device that could rotate the electrode was used during this experiment. The two components: craters obtained through material detaching and welding practices had been optimized in the analysis. The flushing gap was improved through rotation of the electrode. Singh et al.[5] described the Taguchi's approach and utility concept to optimize the multi-machining characteristics simultaneously. They 
discussed a case study on En24 steel turned parts using titanium carbide coated tungsten carbide inserts. They had chosen the three process parameters as, cutting speed, feed and depth of cut. After optimization they found a single optimal condition to get near optimal value of all the response characteristics simultaneously. Mahapatra et al. [6] described the optimization of WEDM process parameters using Taguchi method. The author's optimized material removal rate (MRR), surface finish and cutting width for a rough cut. Taguchi's $\mathrm{L}_{27}$ was used to optimize the individual response characteristic. The experiments were performing on Robofil 100 high precision five axis CNC WEDM, which is manufactured by Charmilles Technologies Corporation. Different settings of six controllable factors such as discharge current, pulse duration, pulse frequency, wire speed, wire tension, and dielectric flow rate were used in the experiments. Discharge current, pulse duration, pulse frequency, wire speed, wire tension and dielectric flow rate and few selected interactions both for maximizations of MRR and minimization of surface roughness in WEDM process using Taguchi Method [7].

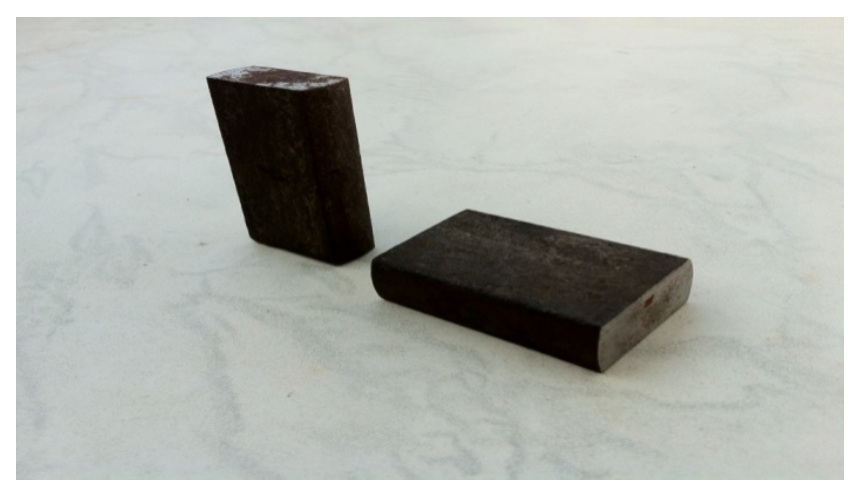

Figure 1. A Photographic views of a workpiece specimen.

\section{Objectives}

The following objectives have been decided for this research work:-

- To find the effect of input parameters on surface roughness of machined test pieces.

- To optimize the process parameters for surface roughness.

- To compare the results obtained by cryogenically treated plain brass wire and zinc coated diffused brass wire.

\section{Experimentation}

The Charmilles Model 290 Wire EDM (WEDM) was used to carry out the experiments. The AISI D3 steel was used as work piece materials for the present experiments. AISI D3 tool steel is a high-carbon, high chromium, oil-hardening tool steel that is characterized by a relatively high attainable hardness and numerous, large, chromium-rich alloy carbides in the microstructure.

\subsection{Input Factors and Their Parameters}

Two types of wire electrodes were used namely brass wire and zinc coated diffused wire.

The various parameters which were taken for experimental study are: pulse width, time between two pulses, wire mechanical tension and wire feed rate. Three levels of each parameter have been taken. Parameter and levels selected are shown in Table 1.

An L9 orthogonal array has been employed according to the taguchi method based robust design philosophy to evaluate the main influencing factors that effect the SR and MRR. A set of four WEDM parameter with three levels of control factor, such as factor (pulse width), (time between two pulses), (wire mechanical tension), and (wire feed rate), have been considered as the controlling factor for machining of D3 with cryogenic treated wires.

\section{Results and Discussion}

\subsection{Signals-to-Noise Ratio for Surface Roughness}

The Table 2 represents the $\mathrm{S} / \mathrm{N}$ for $\mathrm{SR}$ of the workpieces machined by using PBW whereas the Table 3 represents the $\mathrm{S} / \mathrm{N}$ for $\mathrm{SR}$ of the workpieces machined by using $\mathrm{ZCDBW}$.

\subsection{Analysis of Signal to Noise Ratio for SR}

The Table 4 represents the Analysis of variance for $\mathrm{S} / \mathrm{N}$ ratio for SR by using PBW whereas the Table 5 represents the Analysis of variance for $\mathrm{S} / \mathrm{N}$ ratio for SR by using ZCDBW.

Table 1. Input factors and their levels

\begin{tabular}{|c|c|c|c|c|c|c|}
\hline S.No & Level & Units & Symbol & Level 1 & Level 2 & Level 3 \\
\hline 1 & Pulse width & $\mu \mathrm{s}$ & $\mathrm{A}$ & 0.4 & 0.6 & 0.8 \\
\hline 2 & Time b/w two pulses & $\mu \mathrm{s}$ & $\mathrm{B}$ & 9 & 11 & 13 \\
\hline 3 & $\begin{array}{c}\text { Wire mechanical } \\
\text { tension }\end{array}$ & $\mathrm{daN}$ & WB & 0.70 & 1.20 & 1.70 \\
\hline 4 & Wire feed rate & $\mathrm{m} / \mathrm{min}$ & WS & 8.0 & 9.0 & 10.0 \\
\hline
\end{tabular}


Table 2. S/N ratios for with PBW

\begin{tabular}{|c|c|c|c|c|c|c|}
\hline Exp. & $\begin{array}{c}\text { Pulse } \\
\text { width }(\mu \mathrm{s})\end{array}$ & $\begin{array}{c}\text { Time b/w two } \\
\text { pulses }(\mu \mathrm{s})\end{array}$ & $\begin{array}{c}\text { Wire mechanical } \\
\text { tension }(\mathrm{daN})\end{array}$ & $\begin{array}{c}\text { Wire feed rate } \\
(\mathrm{m} / \mathrm{min})\end{array}$ & $\begin{array}{c}\text { Surface } \\
\text { roughness }(\mu \mathrm{m})\end{array}$ & S/N ratio $(\mathrm{dB})$ \\
\hline 1 & 0.4 & 9 & 0.70 & 8.0 & 1.74 & -4.810 \\
\hline 2 & 0.4 & 11 & 1.20 & 9.0 & 1.87 & -5.436 \\
\hline 3 & 0.4 & 13 & 1.70 & 10.0 & 2.00 & -6.020 \\
\hline 4 & 0.6 & 9 & 1.20 & 10.0 & 1.97 & -5.889 \\
\hline 5 & 0.6 & 11 & 1.70 & 8.0 & 2.48 & -7.889 \\
\hline 6 & 0.6 & 13 & 0.70 & 9.0 & 2.02 & -6.107 \\
\hline 7 & 0.8 & 9 & 1.70 & 9.0 & 2.26 & -7.082 \\
\hline 8 & 0.8 & 11 & 0.70 & 10.0 & 2.49 & -7.923 \\
\hline 9 & 0.8 & 13 & 1.20 & 8.0 & 2.23 & -6.966 \\
\hline
\end{tabular}

Table 3. $\mathrm{S} / \mathrm{N}$ ratios for with $\mathrm{ZCDBW}$

\begin{tabular}{|c|c|c|c|c|c|c|}
\hline Exp. & $\begin{array}{c}\text { Pulse width } \\
(\mu \mathrm{s})\end{array}$ & $\begin{array}{c}\text { Time b/w two } \\
\text { pulses }(\mu \mathrm{s})\end{array}$ & $\begin{array}{c}\text { Wire mechanical } \\
\text { tension }(\mathrm{daN})\end{array}$ & $\begin{array}{c}\text { Wire feed rate } \\
(\mathrm{m} / \mathrm{min})\end{array}$ & $\begin{array}{c}\text { Surface roughness } \\
(\mu \mathrm{m})\end{array}$ & $\begin{array}{c}\text { S/N Ratio } \\
(\mathrm{dB})\end{array}$ \\
\hline 1 & 0.4 & 9 & 0.70 & 8.0 & 1.82 & -5.201 \\
\hline 2 & 0.4 & 11 & 1.20 & 9.0 & 1.34 & -2.542 \\
\hline 3 & 0.4 & 13 & 1.70 & 10.0 & 1.56 & -3.862 \\
\hline 4 & 0.6 & 9 & 1.20 & 10.0 & 1.95 & -5.800 \\
\hline 5 & 0.6 & 11 & 1.70 & 8.0 & 1.70 & -4.608 \\
\hline 6 & 0.6 & 13 & 0.70 & 9.0 & 1.93 & -5.711 \\
\hline 7 & 0.8 & 9 & 1.70 & 9.0 & 1.95 & -5.800 \\
\hline 8 & 0.8 & 11 & 0.70 & 10.0 & 1.93 & -5.711 \\
\hline 9 & 0.8 & 13 & 1.20 & 8.0 & 2.02 & -6.107 \\
\hline
\end{tabular}

Table 4. Analysis of variance for $\mathrm{S} / \mathrm{N}$ ratio for $\mathrm{SR}$ with $\mathrm{PBW}$

\begin{tabular}{|c|c|c|c|c|c|c|}
\hline Source & $\begin{array}{c}\text { Sum of } \\
\text { squares }\end{array}$ & $\begin{array}{c}\text { Degree of } \\
\text { Freedom }\end{array}$ & $\begin{array}{c}\text { Mean } \\
\text { square }\end{array}$ & F-value & Status & $\begin{array}{c}\text { Percentage } \\
\text { Contribution }\end{array}$ \\
\hline Pulse width & 5.570 & 2 & 2.785 & 6.9625 & Significant & $51.574 \%$ \\
\hline $\begin{array}{c}\text { Time between two } \\
\text { pulses }\end{array}$ & 2.030 & 2 & 1.015 & 2.5375 & Insignificant & $18.796 \%$ \\
\hline $\begin{array}{c}\text { Wire mechanical } \\
\text { tension }\end{array}$ & 1.320 & 2 & 0.660 & 1.650 & Insignificant & $12.222 \%$ \\
\hline Wire feed rate & 0.280 & 2 & 0.140 & 0.350 & Insignificant & $2.5925 \%$ \\
\hline Error & 1.6 & 4 & 0.400 & & & $14.814 \%$ \\
\hline Total & 10.8 & 12 & & & & 100 \\
\hline
\end{tabular}

Table 5. Analysis of variance for $\mathrm{S} / \mathrm{N}$ ratio for SR with $\mathrm{ZCDBW}$

\begin{tabular}{|c|c|c|c|c|c|c|}
\hline Source & $\begin{array}{c}\text { Sum of } \\
\text { squares }\end{array}$ & $\begin{array}{c}\text { Degree of } \\
\text { Freedom }\end{array}$ & $\begin{array}{c}\text { Mean } \\
\text { square }\end{array}$ & F-value & Status & $\begin{array}{c}\text { Percentage } \\
\text { Contribution }\end{array}$ \\
\hline Pulse width & 6.518 & 2 & 3.259 & 7.457 & Significant & $51.049 \%$ \\
\hline $\begin{array}{c}\text { Time between two } \\
\text { pulses }\end{array}$ & 2.748 & 2 & 1.374 & 3.144 & Insignificant & $21.522 \%$ \\
\hline $\begin{array}{c}\text { Wire mechanical } \\
\text { tension }\end{array}$ & 1.140 & 2 & 0.570 & 1.304 & Insignificant & $8.9285 \%$ \\
\hline Wire feed rate & 0.611 & 2 & 0.305 & 0.697 & Insignificant & $4.7854 \%$ \\
\hline Error & 1.751 & 4 & 0.437 & & & $13.713 \%$ \\
\hline Total & 12.768 & 12 & & & & 100 \\
\hline
\end{tabular}


Table 6. Response table for mean S/N for SR with PBW

\begin{tabular}{|c|c|c|c|c|}
\hline Level & Pulse width & Time between two pulses & Wire mechanical tension & Wire feed rate \\
\hline 1 & $-5.422 *$ & -6.593 & -6.780 & -6.555 \\
\hline 2 & -6.628 & $-5.749 *$ & -6.364 & $-6.208^{*}$ \\
\hline 3 & -7.323 & -7.031 & $-6.299 *$ & -6.610 \\
\hline Delta & 1.901 & 1.282 & 0.551 & 0.402 \\
\hline Rank & 1 & 2 & 3 & 4 \\
\hline
\end{tabular}

Table 7. Response table for $\mathrm{S} / \mathrm{N}$ ratio for SR with $\mathrm{ZCDBW}$

\begin{tabular}{|c|c|c|c|c|}
\hline Level & Pulse width & Time between two pulses & Wire mechanical tension & Wire feed rate \\
\hline 1 & $-3.868^{*}$ & -5.600 & -5.541 & -5.305 \\
\hline 2 & -5.373 & $-4.287^{*}$ & -4.816 & $-4.684^{*}$ \\
\hline 3 & -5.872 & -5.226 & $-4.756^{*}$ & -5.124 \\
\hline Delta & 2.004 & 1.313 & 0.780 & 0.621 \\
\hline Rank & 1 & 2 & 3 & 4 \\
\hline
\end{tabular}

The F-values given in the table suggests the significance of the factors on the desired characteristic. The principle of $\mathrm{F}$ test is that larger the $\mathrm{F}$ value more is the significance of factor. In these experiments the $F_{0.05,2,4}=6.94$. This table value determines significance of a factor at $95 \%$ confidence level, if it is greater than 6.94. In Table 4 the $\mathrm{F}$ value for pulse width is greater than 6.94. Therefore it is significant for SR when machining is done with PBW. The error variation is $14.814 \%$. Similarly, in Table 5 the pulse width has F-value 7.457 which is greater than the table $\left(F_{0.05,2,4}=6.94\right)$. Therefore the pulse width is a significant factor for SR when machining is done with ZCDBW. The error in this case is $13.71 \%$. The rank order based on contribution is same as that obtained earlier through percentage contribution method. The response table for signal-to-noise ratio for all the variables is given in Table 6 for PBW and Table $7 \mathrm{ZCDBW}$.

In the last row of Table 6 and Table 7 ranks have been given to various factors. Higher is the rank, higher is the significance. It has been found that pulse width has the highest (rank 1) and is the most significant factor followed by time between two pulse (rank 2) and wire mechanical tension (rank 3) The wire feed rate has lowest rank and is least affecting the surface finish. The ranks indicate the relative importance of each factor to the response.

\subsection{Effect of Input Parameters on Surface Roughness}

Main effect plots and interactions for surface roughness are shown in figures below. Main effect plot shows the variation of surface roughness with each of variable i.e. pulse width, time between two pulses, wire mechanical tension and wire feed rate. $\mathrm{X}$-axis represents the change in level of variable and $\mathrm{Y}$-axis represents the mean $\mathrm{S} / \mathrm{N}$ ratio of the level or represents the change in resultant response.

\subsubsection{Effect of pulse width on SR}

The effect of both wires electrode on surface roughness is shown in Figure 2. It shows that the value of surface roughness increases when increases the pulse width. The discharge energy increases with the pulse width increase and larger discharge energy produces a larger crater. Then larger crater make a larger surface roughness value. Then it causes poor surface accuracy.

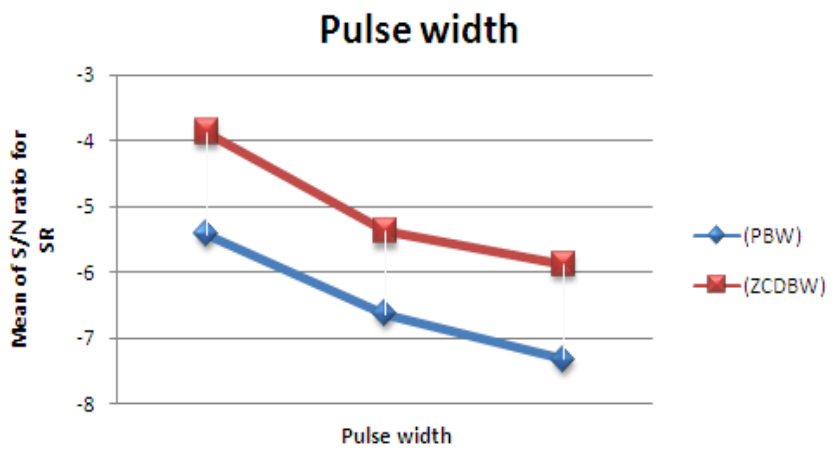

Figure 2. Effect of pulse width on Surface Roughness

\subsubsection{Effect of time between two pulses on SR}

The effect of varying time between two pulses on surface roughness is shown in Figure 3. It shows that the value of surface roughness decreases, when increases its range from 9 $\mu$ s to $11 \mu$ s with the increase in time between two pulses from $11 \mu \mathrm{s}$ to $13 \mu \mathrm{s}$ increases the surface roughness increases. It may be because of higher the value of time between two pulses, lesser is the number of discharges in a given time, resulting in non uniform sparking and lesser number of particles disloged near surface of work materials. Similar result have been reported by Sharma et al. [3], who conducted experiments to optimization of process parameters of cryogenic treated D-3 in WEDM by Taguchi Approach and find that the surface roughness first decrease and then increases with increase in time between two pulses. 
Time $b / w$ two pulses

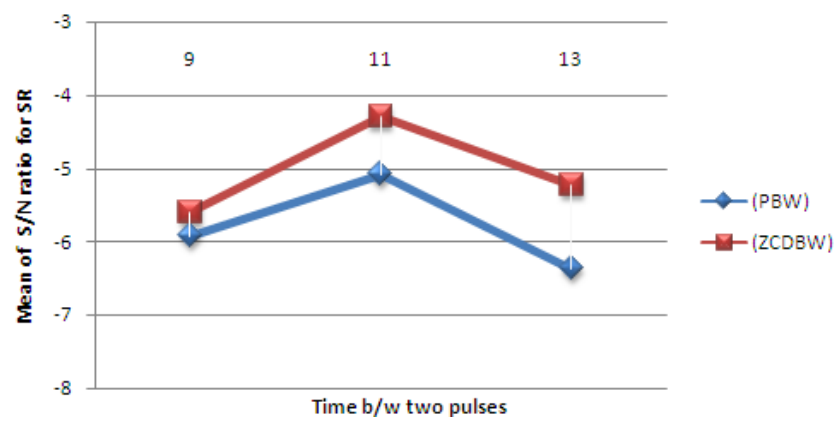

Figure 3. Effect of time between two pulses on SR

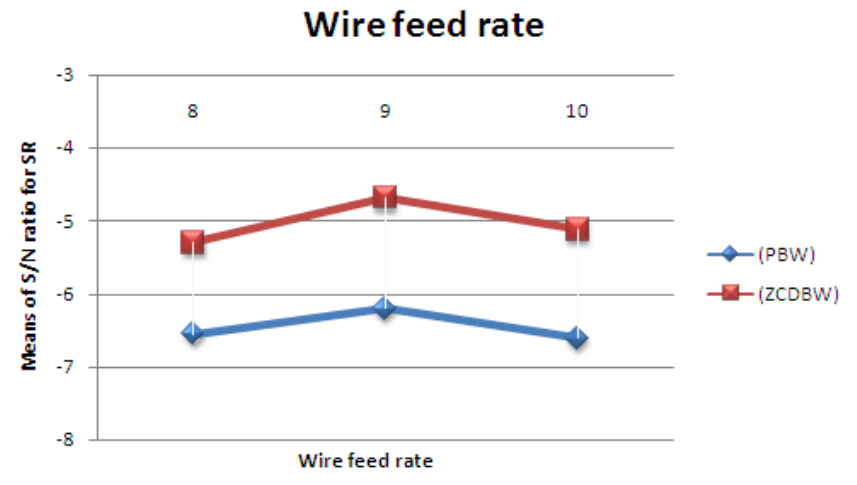

Figure 5. Effect of wire feed rate on Surface Roughness

\section{Conclusions}

The effect of four independent variables (pulse width, time b/w two pulses, wire mechanical tension, and wire feed rate) has been studied for the surface roughness by using two different wires as electrodes in a WEDM machine. The effects of input parameters were evaluated using ANOVA for $\mathrm{S} / \mathrm{N}$ ratios. In addition, main effects plots for $\mathrm{S} / \mathrm{N}$ ratios has been developed and analyzed. The conclusions are:

- The Pulse width found to be most significant factors for surface roughness for both the wires.

- The surface roughness was found to be minimum with (zinc coated diffused brass wire) and maximum with (plain brass wire).

- The surface roughnesses for the test specimen become larger when the pulse width was increased.

- Surface roughness first decreases and then increase with increases in time between two pulses.

- Surface roughness quality of the machined part is improved due to increase of wire tension.

- It can be conducted that deep cryogenically treated plain brass wire produces more surface roughness than zinc coated diffused brass wire.

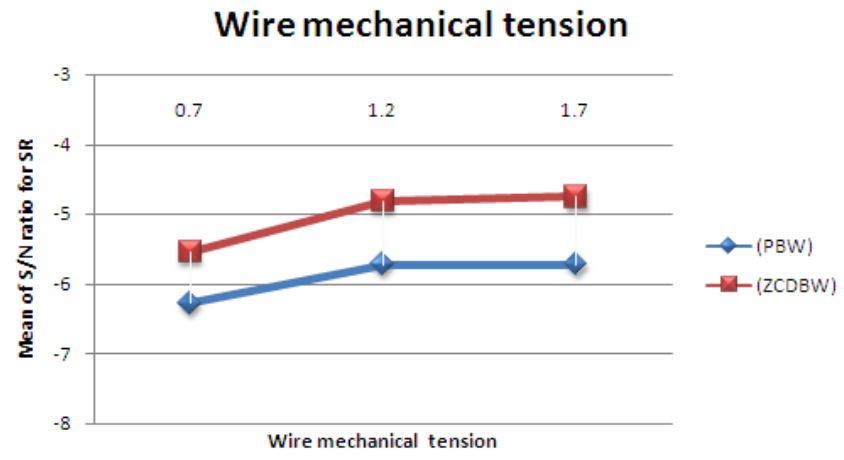

Figure 4. Effect of wire mechanical tension on SR

\subsubsection{Effect of wire feed rate on SR}

The effect of varying wire feed rate on surface roughness is shown in Figure. 5. It shows that with wire feed rate the SR has first decreases and then increases. It may be due more vibrations at more wire feed rate. The results are inline with Rao et al. [8].

\section{REFERENCES}

[1] Lahaneet, S.D., Rodge, M.K. and Sharma, S.B. Multi-response optimization of Wire-EDM process using principal component analysis, IOSR Journal of Engineering, Vol. 2, 8, 38-47, 2012.

[2] Gill, A.S., Thakur, A. and Kumar, S. Effect of cryogenic treatment on the surface roughness of OHNS die steel after WEDM, International Journal of Applied Engineering Research, Vol. 7, 11, 2012.

[3] Sharma, N. and Khanna, R. Optimization of process parameters of cryogenic treated D-3 in WEDM by Taguchi Approach, International Journal of Engineering Research and Applications Vol. 1, 3, 546-553, 2011.

[4] Purcar, C. and Simion, C. Studies about the roughness of the surfaces machined by EDM, Ronanian Association Of 
Nonconventional Technologies, Vol. 2, 78-81, 2012.

[5] Singh, P. L. and Singh, J. Effects of Cryogenic Treatment on High Speed Tool Steels, Journal of Engineering and Technology', Vol. 1, 2, 88-93, 2011.

[6] Mahapatra, S.S. and Patnaik, A. Optimization of wire electrical discharge machining (WEDM) process parameters using Taguchi method, International Journal of Advance manufacturing Technology, Vol. 28, 22-429, 2006.
[7] Anta, M.T., Soo, S.L., Aspinwall, D.K., Jones, D. and Perez, R. Productivity and workpiece surface integrity when WEDM aerospace alloys using coated wires, Procedia Engineering Vol. 19, 3-8, 2012.

[8] Rao, P.S., Ramji, K. and Satyanarayana, B. Effect of WEDM conditions on surface roughness: a parametric optimisation using taguchi method, International Journal of Advanced Engineering Sciences and Technologies. Vol. 6, 1, $41-48$, 2011. 